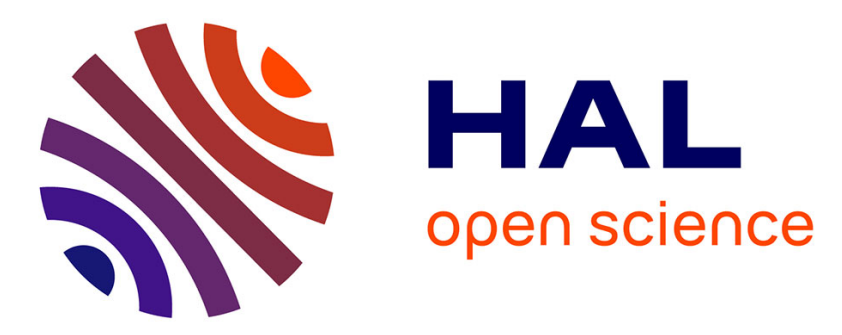

\title{
The Sale of Alcohol in Denmark - Recent Developments and Dependencies on Prices/Taxes.
}

\author{
Lisbeth La Cour, Anders Milhoj
}

\section{To cite this version:}

Lisbeth La Cour, Anders Milhoj. The Sale of Alcohol in Denmark - Recent Developments and Dependencies on Prices/Taxes.. Applied Economics, 2009, 41 (09), pp.1089-1103. 10.1080/00036840601019174. hal-00582029

\section{HAL Id: hal-00582029 \\ https://hal.science/hal-00582029}

Submitted on 1 Apr 2011

HAL is a multi-disciplinary open access archive for the deposit and dissemination of scientific research documents, whether they are published or not. The documents may come from teaching and research institutions in France or abroad, or from public or private research centers.
L'archive ouverte pluridisciplinaire HAL, est destinée au dépôt et à la diffusion de documents scientifiques de niveau recherche, publiés ou non, émanant des établissements d'enseignement et de recherche français ou étrangers, des laboratoires publics ou privés. 


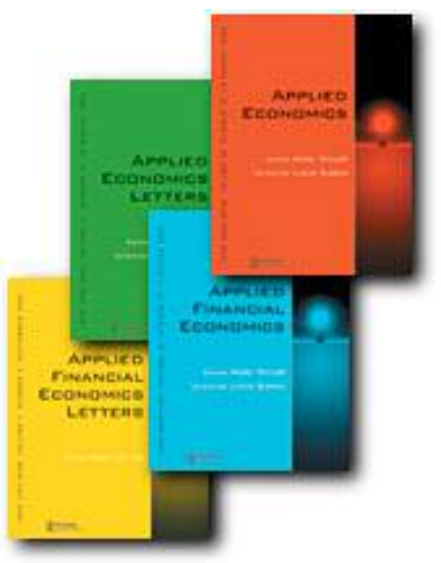

The Sale of Alcohol in Denmark - Recent Developments and Dependencies on Prices/Taxes.

\begin{tabular}{|r|l|}
\hline Journal: & Applied Economics \\
\hline Manuscript ID: & APE-05-0697.R1 \\
\hline Journal Selection: & Applied Economics \\
\hline JEL Code: & $\begin{array}{l}\text { C32 - Time-Series Models < C3 - Econometric Methods: } \\
\text { Multiple/Simultaneous Equation Models < C - Mathematical and } \\
\text { Quantitative Methods, D12 - Consumer Economics: Empirical } \\
\text { Analysis < D1 - Household Behavior and Family Economics < D - } \\
\text { Microeconomics }\end{array}$ \\
\hline Keywords: & Alcohol, Market shares, Taxes, Prices, Multivariate cointegration \\
\hline
\end{tabular}

powersd by ScholarOne
Manuscript Central $^{\text {tw }}$ 


\title{
The Sale of Alcohol in Denmark - Recent Developments and Dependencies on Prices/Taxes ${ }^{1}$.
}

Lisbeth la Cour

Department of Economics

Copenhagen Business School

Solbjerg Plads 3

DK2000 Frederiksberg

Denmark
By

Anders Milhøj
Department of Economics
University of Copenhagen
Studiestræde 6
DK 1455 Copenhagen K
Denmark

\begin{abstract}
:
How do prices affect the choice of types of alcohol in Denmark? We study the Danish sale of alcoholic beverages in a time series framework. First, we look at annual data from 1980 investigating the hypothesis of a fairly stable level of sales. We conclude stationarity of sales and we also find that the income elasticity of total sales has been zero. Secondly, we analyse the composition of the alcohol sale between beer, wine and spirits in a multivariate model conditional on the development in prices. For this analysis we use Johansen cointegration techniques. Again we test that income can be omitted from the model and we use the model to derive the effects on the composition of alcohol sales of three different sets of changes in the alcohol taxation.
\end{abstract}

Corresponding author: Lisbeth la Cour, e-mail llc.eco@cbs.dk, phone: +45 38152488

\footnotetext{
${ }^{1}$ The authors would like to thank an anonymous referee for valuable comments and suggestions.
} 


\title{
The Sale of Alcohol in Denmark - Recent Developments and Dependencies on Prices/Taxes.
}

\author{
1. Introduction \\ In the following we shall analyse the sale of alcohol in Denmark. First we want to \\ convince the reader that the total sale of alcohol in Denmark since 1980 has been fairly \\ stable. This is an interesting issue as the sale remained constant in contrary to what was \\ expected by most people while wealth has increased and prices of alcohol have in fact \\ lowered due to large reductions in the taxes on alcohol during these 25 years. It seems \\ that the alcohol consumption has not in this period been severely restricted by economic \\ constraints. A non-economical conclusion is that alcohol related health problems did not \\ increase following the tax reductions.
}

Studies of the sale of alcohol or alcohol consumption has taken two directions in the literature. One is the more classical economic direction based on an investigation of household consumption behaviour within the framework of a microeconomic model. Many papers within this tradition are based on either some version of the AIDS system, see e.g. Edgerton et al. (1996) for the Nordic countries, Blake and Nied (1997) for the UK, Andrikopoulos and Loizides (2000) for Cyprus or Eakins and Gallagher (2003) for Ireland or the Rotterdam model, see e.g. Selvanathan (1991) for a cross-country comparison and Selvanathan and Selvanathan (2004) for Australian data. Both of these model approaches lead to estimation of budget share equations for categories of alcoholic (or other) beverages with either prices or log prices and income as explanatory variables. Also additional explanatory variables like e.g. demographic factors are some times included in the models. 
One special feature of alcohol, however, is the possibility of using a meaningful physical unit of measurement for aggregation over sub categories (e.g. beer, wine and spirits) instead of relying on aggregation- and index number theory (see e.g. Lewbel (1996) or Lewbel (1997) for a theorem for aggregation over commodities). We will follow this tradition of performing aggregation over sub categories by units of $100 \%$ alcohol equivalents. Another study that apply this approach is McGuinness (1980) who studies alcohol consumption in the U.K., and this approach is also supported heavily by the Nordic tradition of studies in alcohol problems, see e.g. Bentzen and Smith (2005), Bentzen and Smith (2004), Bentzen, Eriksson and Smith (2001) and Milhøj(1996) or Bask and Melkersson (2004). Furthermore, aggregation of this type is mentioned in the introduction of the paper by Selvanathan and Selvanathan (2004). Aggregation by conversion to physical units may be viewed as controversial by some and it can be interpreted as if it does not matter for the Danes (or consumers in general) what they drink as long as it is alcoholic. One argument for the approach could be, however, that the legal rules for drunk driving relates to the content of alcohol in the various categories of beverages rather than to the type of beverage. Also from a health perspective there is an interest in the pure alcohol quantities rather than the category of origin. Our aggregation approach is also interesting as aggregation over some common unit in the way we do is possible in other situations as well, for instance various ways of holiday spending where the common unit could be days or transportation where the common unit could be length of journey.

The indication in our data that the total market for alcohol has been constant for the last 25 years happens on the top of some drastic changes in the sale of beer and wine, as the sale of beer has decreased to half the level in 1980 while the sale of wine has doubled. 
The fact that these two developments cancel each other when measured in $100 \%$ alcohol units is in accordance with the performed aggregation over alcohol equivalents.

In the second part of the paper we want to model the sale of beer and wine as shares of the total sale of alcohol. These market shares are interesting from a business perspective, as most of the beer and spirits sold in Denmark is domestically produced, while wine is imported. Some of the changes in taxation were performed as the previous taxation protected the domestic beverages in a way that was not allowed in the EU, and hence both the changes in taxation and the taste trends indicate an increasing market share of wine, which is unfavourable for the Danish production and employment. One point of the paper is to distinguish between these two effects that have happened simultaneously.

By modelling the system of the beer-share and the wine-share (the spirits share being redundant) we are able to split the total development into a part that can be ascribed to changes in the relative prices and a part that can be explained by changes in taste and drinking habits specified as a trend. Unlike other countries Danish data gives a unique possibility to derive the consequences of changing price relations for the three types of alcohol, as the taxation has changed dramatically for the three categories on different points in time.

A small forecasting exercise shows that the final model is fairly good at predicting changes in the shares due to price changes. Finally, the effects on the market shares and hence the consequences for the Danish breweries and distillers of hypothetical changes in the taxation of alcohol are discussed, e.g. a unified taxation on alcohol content independent of type of beverages as suggested by the European Commission (2004). Also a reduction in the taxes to make them match the German level - a possibility often mentioned in the Danish debate - is investigated. 
The rest of the paper is organized as follows: In section two we discuss our data and give a visual presentation of them. Next, in section three we analyse our hypothesis of a fairly constant level of the sale of alcohol on yearly data from 1980 till 2004. In section four we work with the quarterly data set and suggest a parsimonious dynamic (VECM) model of the market shares of beer and wine. In section five we demonstrate that this model has promising forecasting properties. In addition, section five contains calculations of predicted effects of hypothetical yet realistic changes in the taxation of alcohol. Finally, a section with a summary and conclusions can be found.

\section{The Data}

We focus primarily on the time period after 1980 as this reflects the period of interest for our first hypothesis. This means that in graphs etc. we primarily use yearly data for this time period but in some situations we show historical data too to set the stage for the analysis. When turning to the market shares of the categories of alcohol (beer, wine and spirits) we have to switch to quarterly observations in order to get a sufficient number of observations for a proper statistical model. Unfortunately, the quarterly quantity figures are not available before $19903^{\text {rd }}$ quarter so for this analysis we move the starting point of the sample to this date.

Based on the yearly data the total sale of alcohol in Denmark for the last 25 years is displayed in figure $1 \mathrm{~A}$ to give the reader the impression that our hypothesis of a fairly constant sale of alcohol for this period seems to be supported. In figure 1B we extend the time period of the graph to show that this has not always been the case. Figure 1B starts in 1903 where the series of official numbers starts. Notice that for such a long period of time it is necessary to report the figures in per capita terms (persons over age of 14) as 
the Danish population has almost doubled. From 1980 onwards this is not necessary as discussed below and in the analysis of the post 1980 data we do not look at the data per capita.

$<$ Figure $1 \mathrm{~A}$ about here $>\quad<$ Figure $1 \mathrm{~B}$ about here $>$

The figures illustrate that some major changes have taken place in the total sale of alcohol since the beginning of the twenties century. Heavy regulations after World War I led to a much lower sale which after World War II again started to increase. Hence for the whole period of about 100 years a hypothesis of a fairly constant sale of alcohol would clearly not be accepted. Using unit root tests Bentzen et al (2001), (2004), (2005) actually conclude that there is not much evidence of mean reversion in the consumption of alcohol when the period from just around 1900 and up till today is considered. For a complete exposition of the structure of the Danish alcohol market in a period of 100 years and for further references, see Thorsen (1990). After the rapid growth from about the mid-50's until around 1980 the sale has stabilized. So judged from this graph it seems a reasonable hypothesis that the total sale of alcohol has been fairly constant for the last 25 years. What happened between 1955 and 1980 is not of interest to this study, but tentative explanations are of the following kind: Consumption of alcohol by women seems to have increased in this period. Wealth and income have increased in this period and with an income elasticity greater than zero the total consumption of alcohol has increased as well. Curiously, one of the findings in the present study is that after this period the income elasticity of alcohol has decreased towards zero, see figure 2 for a preliminary picture ${ }^{1}$.

\footnotetext{
${ }^{1}$ For a study that allows demand elasticities to change over time, see Gallet (1999).
} 
$<$ figure $2>$ about here

As it is quite difficult to correct for all these factors we decided to skip the period from $1955-1980$ and focus on the sale of alcohol from 1980 to 2004. Seeing the total sale of alcohol in relation to the population size is quite normal in studies of sale of alcohol (see e.g. Bentzen and Smith (2005)) but as indicated by figure 1B showing the total Danish sale of alcohol per person over 14 years the picture from 1980 until today is not much different from the picture in figure $1 \mathrm{~A}^{2}$.

The data for the total sale of alcohol on a yearly basis is published by Statistics Denmark. Figures for the sale of beer, wine and spirits are made comparable (as mentioned in the introduction) by using the same unit: $100 \%$ alcohol equivalents. The data is collected as the taxes are paid thus indicating the quantity of alcohol sold to the retail sector and not necessarily that sold to the consumer. This implies e.g. that around new year the inventory building in shops may push some figures towards December. Given that such movements are of similar size each year it should not cause problems for the analysis. It is of course an important point, that the figures we use are sales figures and not consumption figures. The border trade is highly important for Denmark as the prices in Germany are much lower leading to a both legal and illegal private import from Germany. But as the prices of alcoholic beverages in Sweden and Norway are much

\footnotetext{
${ }^{2}$ Notice, however, from figure 1A and 1B that the development in the total sale of alcohol since 1980 appears even more constant when corrected for the populations size.
} 
higher than in Denmark we also see a considerable private export from Denmark. So the sale of alcohol in Denmark is also affected by the price levels and border trade regulations in Norway and Sweden. One could say that the Danish alcohol market geographically also covers the southern parts of Sweden but not the southern part of Jutland with easy access to cheap German alcohol. But even if the market is not well defined as the Danish market it still covers most of the Danish population and hence is of interest. The illegal production of alcohol is of no importance. For English references to the Danish border trade see e.g. Bygvrå (1998) or Milhøj (1996).

The data from Statistics Denmark also covers the distribution of the total sale of alcohol into the categories beer, wine and spirits. As the sale is measured in $100 \%$ alcohol the sale of the three types of alcohol are easily compared. The development in the market shares of these categories since 1980 is shown in figure $3^{3}$.

$<$ Figure 3 about here $>$

Figure 3 shows that while the share of sale of spirits has remained fairly constant over the period, beer has experienced a fall while wine shows an increasing upward trend. In addition to the yearly data we have access to quarterly data of the same kind but only from $19903^{\text {rd }}$ quarter to 4 th quarter of 2004 . The development in the category market shares over time is shown in figures 4.

$<$ Figure 4 about here $>$

\footnotetext{
${ }^{3}$ Notice that the shares will be unaffected by whether we analyse sales of alcohol per person above the age of 14 or not.
} 
When going from yearly to quarterly data the development in the series becomes noisier, clearly indicating that seasonality needs to be taken into account in the analysis. The seasonal components show that the sale of all types of alcohol are low in the first quarter and moreover the market shares of beer and spirits are higher in the fourth quarter as a part of the Danish Christmas traditions. Otherwise the conclusions from before still seem to hold: The share of beer has decreased and the share of wine has increased. For most of the period the share of spirits has been fairly constant yet the reduced taxes on spirits in the autumn of 2003 has increased the level somewhat in the last part of the sample.

As for any other good it is quite obvious that prices somehow affects the sale of the various categories of alcoholic beverages. Below the development in quarterly index numbers for the prices of beer, wine and spirits are shown graphically. Moreover the index for the overall consumer prices is shown for comparison.

$<$ Figure 5A about here $>$

The prices we use are the index numbers published by Statistics Denmark. The composition of the indices reflects the composition of the sale within each type of alcohol, so that for e.g. spirits the price index is a weighted average of the prices of Danish snaps and Danish bitter, which in total gives around $80 \%$ of the total sales of spirits leaving the last $20 \%$ for imported brands of cognac, whiskey etc.

As is evident from the figure the raise in the price indices caused by the overall inflation is the main reason for price movements in the period before 1990. Since 1990 the prices appears to be rather constant even if the overall price level is still increasing although at a more moderate speed. The various tax changes that took place during the sample period 
are clearly seen as downward jumps in the corresponding series. These are quite important reductions of the beer and wine taxations in the nineties and a drastic reduction of the taxation of spirits in 2003.

$<$ Figure 5B about here $>$

\section{Analysis of the total sale of alcohol in Denmark.}

To test the hypothesis that the total consumption of alcohol in Denmark has remained constant we study the temporal dependence in the series by means of the autocorrelation function and unit root and stationarity tests. Finding a unit root i.e. a stochastic trend in the series will violate our hypothesis. Even though most tests developed for investigating the hypothesis of a unit root are asymptotic in nature and therefore not really applicable for a time series as short as ours, we still perform the tests but we are careful not to draw too firm conclusions based on these tests. We will use them as guidelines rather than as actual tests. To decide the robustness of our conclusion we add a cointegration analysis of the bivariate system containing the total sale of alcohol and real income even though we more informally argue the income has not affected this sale for the period under study.

\subsection{The autocorrelation function (ACF) for the total sale of alcohol in Denmark.}

The autocorrelation function shows the correlation of a time series with past values of the series itself. In figure 6 autocorrelations for the total sale of alcohol are shown.

$<$ Figure 6 about here $>$

The figure supports our hypothesis that there is no strong temporal dependence in the total sale of alcohol in Denmark since 1980. In figure 6 there is only one significant 
autocorrelation at lag 1 . The value of this correlation is around 0.5 and thus quite far from the value "one" which would imply a unit root (in an AR(1) process). Even though our series is quite short and the significance bounds presented in the graphs are based on asymptotic distributional results, our conclusion so far is that the data does not contradict our hypothesis. Next, we perform two types of numerical tests for nonstationarity/stationarity. The augmented Dickey-Fuller (ADF) test is by far the most popular univariate unit root test. For our purpose this test suffers from the fact that the null is that the series of interest has a unit root and following traditional procedures of doing inference one will thus favour the null until strong evidence against it is available. As our preferred null is that of stationarity using the ADF test is not optimal. Hence in addition we will run a test known as the KPSS test (see Kwiatkowsky et al (1992)) with stationarity as the null. For both the ADF test and the KPSS test we have to decide on the exact form of the model used: should the alternative be a stationary series with a mean that may be different from zero or should we allow for a deterministic trend in the alternative. Based on the initial graphs of the data there is no clear need for a trend hence we will concentrate on a model without a trend.

The ADF test is based on the regression equation:

$$
\Delta x_{t}=\alpha_{0}+\alpha_{1} x_{t-1}+\sum_{i=1}^{k} \lambda_{i} \Delta x_{t-i}+\varepsilon_{t}
$$

Where $\mathrm{x}$ is the series of interest, the $\alpha$ 's and $\lambda$ 's are parameters and $\varepsilon$ is a stochastic error term which is assumed to be iid normal. The hypothesis of a unit root is the hypothesis that $\alpha_{1}$ equals zero. The t-test statistic (called $\tau$ ) for testing this hypothesis follows a non- 
standard distribution which has been tabulated for various sample sizes. The results for the total sale of alcohol in Denmark are given below:

Table 1: Results of the ADF test.

\begin{tabular}{|l|c|c|c|}
\hline & 0 lagged changes & 1 lagged change & 2 lagged changes \\
\hline$\tau$-statistic & -3.26 & -2.65 & -2.72 \\
\hline p-value & 0.0286 & 0.0970 & 0.0868 \\
\hline
\end{tabular}

We see that when testing at a $10 \%$ level we are able to reject the null of a unit root and conclude stationarity of the series. Given that the null is opposite to what we really want it to be it does not seem inappropriate to use a test level of $10 \%$. Moreover, the short sample size indicates that a test level larger than 5\% should be applied. The conclusion is not affected by the number of lagged differences included in the model (strictly speaking the residuals should be white noise and by looking at the ACF in figure 6 no autocorrelation is significant after lag 1 so the first column seem to be the most relevant one in our case).

To reinforce the picture the KPSS test is run. In this test the null is that of stationarity our preferred null. The test allows for correction for autocorrelation by non-parametric means. The equation on which the test is based includes an intercept term but no trend.

Table 2: Results of the KPSS test

\begin{tabular}{|l|l|l|l|}
\hline & No serial correlation & Medium $^{\text {a correlation }}$ & High $^{\text {a correlation }}$ \\
\hline Statistic & 0.25 & 0.13 & 0.21 \\
\hline
\end{tabular}

a: In the test that allows for medium serial correlation the truncation parameter is set to 4 while it is set to 8 for the high correlation case.

None of the statistics are significant even at the $10 \%$ level (critical value $=0.347$ ). 
The results of the table indicate that we find no significant values of the test statistic irrespectively of how much autocorrelation we allow for. Hence the series is considered stationary when the KPSS test is used.

Finally, we set up a bivariate system with the total sale of alcohol and real income as the two variables. The hypothesis we want to test in this system is that we have just one cointegration relation which is just the total sale of alcohol such that the stationarity of this variable is not affected by income (supporting the visual inspection that real income has increased during this period while the total sale of alcohol has remained fairly constant, see figure 2 above.

The analysis is done conditional on a restricted ${ }^{4}$ trend allowing for the possibility that real income is trend-stationary. The model is of the VAR-type that allows for nonstationary and possibly cointegrated series. Estimation and hypothesis testing follow the methods outlined by Johansen (1995). The model in VECM form can be written as:

$$
\Delta \mathrm{X}_{\mathrm{t}}=\Pi \mathrm{X}_{\mathrm{t}-1}+\Gamma_{1} \Delta \mathrm{X}_{\mathrm{t}-1}+\ldots+\Gamma_{\mathrm{k}-1} \Delta \mathrm{X}_{\mathrm{t}-\mathrm{k}+1}+\mu+\varphi \mathrm{D}_{\mathrm{t}}+\varepsilon_{\mathrm{t}}
$$

where $\mathrm{X}$ is the two-dimensional vector of the series of interest, $\mu$ is an intercept term and $\mathrm{D}$ contains the restricted trend. The matrices in front of the lagged $\mathrm{X}$, the lagged changes in $\mathrm{X}$ and the dummies in $\mathrm{D}$ are matrices of parameters. The error vector, $\varepsilon$, is assumed to be iid normal with mean 0 and a covariance matrix $\Omega$. A preliminary set of misspecification tests for this model indicate no problems with the model ${ }^{5}$.

\footnotetext{
4 A restricted linear trend in an equation is a trend that is restricted to appear in the long-run relations only - which implies that the model does not allow for quadratic trends in the levels of the series. A linear trend is still allowed through the constant term of the equation.

${ }^{5}$ The results are available from the authors on request.
} 
To determine the stationarity properties of the set of variables we perform the Johansen Trace test. Notice that also this test starts with a hypothesis of non-stationarity and only if this hypothesis is rejected we go on to consider the possibility of one or more stationary relations. With a small sample and an "opposite" hypothesis we again allow for a higherthan-conventional level of significance. In addition, the final decision concerning the number of stationary relations will also rely on an inspection of the modulus of the roots of the companion matrix.

Table 3: Results of the Johansen Trace tests.

\begin{tabular}{|c|l|r|r|r|r|r|}
\hline $\mathbf{p}-\mathbf{r}$ & $\mathbf{r}$ & \multicolumn{1}{|l|}{ Eigenvalue } & \multicolumn{1}{l|}{ Trace } & \multicolumn{1}{l|}{ p-value } & \multicolumn{1}{l|}{ Trace* $^{*}$} & \multicolumn{1}{c|}{ p-value* } \\
\hline 2 & 0 & 0.47 & 19.65 & 0.429 & 18.84 & 0.297 \\
\hline 1 & 1 & 0.16 & 4.29 & 0.702 & 4.23 & 0.710 \\
\hline
\end{tabular}

The trace column is the original test statistic of the trace test and the trace* is the Bartlett corrected version (see Johansen (2002)).

In order to accept any cointegration i.e. reject the hypothesis of two unit roots in this system we have to accept working with a significance level of around 30\%. Even with the points we have made so far this is a somewhat high level, so in order to support our tentative conclusion of one cointegration relation we rely also on the sizes of modulus of the roots of the companion matrix. They are 0.692 and 0.366 respectively. Deciding that at most the first of these is approximatively one we feel quite confident in concluding the existence of one cointegration relation. One cointegration relation means that something is stationary in this system and our hypothesis is that it is just the total sale of alcohol that is stationary. Testing this hypothesis by a (Bartlett-corrected) likelihood ratio test i.e. imposing zero restrictions on the coefficient of income and the trend in the cointegrating 
relation leads to non-rejection: $\mathrm{Q}=3.69 ; \mathrm{p}$-value $=0.16^{6}$. For robustness we also test the competing hypothesis that real income is trend stationary. This hypothesis is rejected (pvalue $=0.01$ ) so we feel again quite confident that the evidence is in favour of the conclusion that the total sale of alcohol is stationary and hence has been fairly constant for the last 25 years. The additional conclusion that the income elasticity of the sale of alcohol has been close to zero since 1980 is also not rejected by the data ${ }^{7}$.

To summarize the investigation of the time series properties of the total Danish consumption of alcohol we conclude that for the period from 1980 and till today (the yearly data) the data does not contradict the hypothesis of stationarity whether studied graphically or by means of ADF or KPSS. We reach the same conclusion when a bivariate cointegration analysis is done based on the total sale of alcohol and real income.

\section{The distribution of the total Danish consumption of alcohol among the categories: beer, wine and spirits.}

As indicated earlier our hypothesis for the market shares is that both the prices and possibly also changes in taste and habits have affected their development over time. Whether changes in taste and habits comes from changes in income (we can afford to drink wine instead of beer) or is rather driven by more cultural factors described by a time trend (health considerations; people having less beer for lunch and rather wine than beer for dinner) will be discussed in the analysis. The focus is on the years after 1990 with quarterly data available due to the low number of observations in the yearly data set.

\footnotetext{
${ }^{6}$ Imposing restrictions for weak exogeneity of income on top of the restrictions on the cointegration relation also leads to non-rejection .

${ }^{7}$ If this had not been the case then both the sale of alcohol and income would have entered the cointegrating relation of the bivariate model.
} 
With only about 25 observations as we have for the yearly data more sophisticated time series techniques will be difficult to apply here. Moreover the changes in taxation were introduced at the end of a quarter (July $1^{\text {st }}$ and October $1^{\text {st }}$ ) and not around New Year. Notice that a model for market shares is something quite different from our investigation of the total sale of alcohol in Denmark in section three and hence is not affected by the conclusion we derived in that section.

\subsection{Analysis of an unconditional system.}

As the sales of beer, wine and spirits sum to the total sale of alcohol the development of the series of market shares are necessarily connected and we choose to apply a system analysis. We choose to model the shares of beer and wine making the share of spirits redundant given the total sale, leaving us with a two dimensional system. A necessary feature of a time series in order to enter a traditional regression analysis is stationarity as otherwise the results of the analysis may be "spurious" (see Granger and Newbold (1974)). Non-stationarity of a stochastic type may be handled by cointegration techniques while deterministic non-stationarity (trend stationarity or stationarity around a trend with deterministic shifts) needs other tools. We believe that the non-stationarities observed in the price series are mainly of a deterministic (politically induced tax changes) nature and as a result we prefer to condition on the three price series. Also based on more common sense economic considerations income should be considered a conditioning variable. Whether conditioning is also statistically valid can in fact be checked by starting out with an analysis of a six dimensional system in which the prices are viewed as stochastic and income is included. Hence stationarity will be addressed in this preliminary study of a six dimensional system of the share of beer, the share of wine, the prices of beer, wine and spirits respectively and income. The analysis is done conditional on a restricted trend. 
We use a VAR(1) model to perform the analysis (see equation (2) above). For the present data set the $\mathrm{X}$-vector is of dimension six. With quarterly data, matrix $\mathrm{D}$ in the equation now also contains a set of centered seasonal dummies.

First we check to what extent the assumptions concerning the error term are fulfilled. This is done by a battery of multivariate and univariate misspecification tests ${ }^{8}$. In general the model is well-specified only normality of the price series is not accepted. The nonnormality of the price series is just what we would expect given that the nature of these series are more deterministic than stochastic, as the shifts according to changes in taxation are dominant.

Next, we perform the Johansen trace test in order to test for the cointegration rank. When using the Johansen trace test we have to keep in mind that the distributional results of this test statistic is of an asymptotic nature while our sample period is limited to 58 observations. (Fortunately, the Johansen trace test is not heavily affected by the nonnormality of the errors). Hence we report both the traditional trace test and the Bartlett corrected version. Furthermore we will present the modulus of the roots of the characteristic polynomia and finally we will show graphs of the candidates for cointegrating relations.

\footnotetext{
${ }^{8}$ The exact results of the various tests are available for the authors upon request.
} 
Table 4: Results of the Johansen trace test.

\begin{tabular}{|c|l|r|r|r|r|r|}
\hline $\mathbf{P}-\mathbf{r}$ & $\mathbf{R}$ & \multicolumn{1}{|l|}{ Eigenvalue } & \multicolumn{1}{l|}{ Trace } & \multicolumn{1}{l|}{ p-value } & \multicolumn{1}{l|}{ Trace $^{*}$} & \multicolumn{1}{l|}{ p-value* } \\
\hline 6 & 0 & 0.64 & 144.30 & 0.000 & 135.87 & 0.002 \\
\hline 5 & 1 & 0.58 & 85.44 & 0.084 & 81.42 & 0.151 \\
\hline 4 & 2 & 0.26 & 36.15 & 0.939 & 34.85 & 0.959 \\
\hline 3 & 3 & 0.15 & 19.08 & 0.970 & 18.60 & 0.976 \\
\hline 2 & 4 & 0.10 & 9.63 & 0.938 & 9.49 & 0.938 \\
\hline 1 & 5 & 0.06 & 3.60 & 0.796 & 3.58 & 0.796 \\
\hline
\end{tabular}

The trace column is the original test statistic of the trace test and the trace* column is the Bartlett corrected version (see Johansen (2002)).

Based on both the original trace test and the Bartlett corrected version we can at a $20 \%$ level conclude that two relations are stationary. Notice also that there is a fairly big drop in the size of the eigenvalues when moving from the second $(0.58)$ to the third $(0.26)$, which is an additional indication that something happens around here supporting the conclusion of $r=2$.

The results of our additional indicators are:

Table 5: Modulus of the roots of the companion matrix before and after a rank of $r$ $=\mathbf{2}$ is imposed:

\begin{tabular}{|l|r|r|r|r|r|r|}
\hline & Root 1 & Root 2 & Root 3 & Root 4 & Root 5 & Root 6 \\
\hline $\begin{array}{l}\text { No rank } \\
\text { restriction }\end{array}$ & 0.927 & 0.927 & 0.755 & 0.491 & 0.063 & 0.029 \\
\hline $\mathbf{r = 2}$ & 1.000 & 1.000 & 1.000 & 1.000 & 0.057 & 0.031 \\
\hline
\end{tabular}

The table shows that initially three maybe four of the roots are close to one. After imposition of four unit roots the remaining roots a very small supporting our conclusion of the presence of two long-run stationary relations (the cointegrating relations). 
Graphs of the two cointegration relations are shown in figures 7A and 7B. Again the picture is that of fairly stationary series that tend to cross the mean value quite often. This holds true whether (lower panel) or not (upper panel) we correct for the short-run dynamics.

$<$ Figure 7A about here $>$

$<$ Figure $7 \mathrm{~B}$ about here $>$

So based on various indicators a choice of $r=2$ seems appropriate and we continue the analysis based on this choice.

Next step is to perform the formal likelihood ratio (LR) test for weak exogeneity of the price series and to further investigate the role of the income variable in the system. As normality is not fulfilled the distributional assumptions for this test may not be exactly met yet we run the test anyway to see what it indicates. The hypothesis of the test is that rows three to five of the $\alpha$-matrix contain zeros - i.e. the price series do not adjust to the disequilibrium errors of the system (or: deviations from the cointegrating relations do not enter the price equations significantly).

The test statistic for the null of weak exogeneity of the prices becomes $Q=4.82 ; p$-value $=0.57$. To investigate the role of the income variable in the system i.e. to see whether this variable is at all needed in the analysis we test the composite hypothesis that the coefficients of income in the two cointegrating relations are zero (excluding income from the long-run relations) while at the same time the coefficients in the last row of the $\alpha$ matrix also is zero (weak exogeneity of income). The LR-test statistic for this hypothesis becomes: $\mathrm{Q}=19.70$ with $\mathrm{p}$-value $=0.03$. So without a Bartlett correction for this test (it has not been developed yet) which presumably would increase the p-value of the test 
(results for other types of tests of restrictions on the beta-vectors points towards rejection of the null too often at conventional test levels, see e.g. Johansen (2000)) we believe even with a p-value a bit below 5\% - that the data is not strongly rejecting the composite hypothesis. For a VAR(1) model there is no possibility for additional short-run effects from income on the market shares and we therefore conclude that income adds nothing to the model and remove this variable from the system for the remaining part of the analysis. Hence it seems sufficient to use a simple trend to capture the changes in market shares induced by changes in taste and habits.

Hence without income and with prices being weakly exogenous we argue for continuing the analysis within a two-dimensional system for the series of market shares conditioned on the prices. Compared to the model in (2) the system we now focus on is:

$$
\Delta \mathrm{X}_{\mathrm{t}}=\Pi \mathrm{X}_{\mathrm{t}-1}+\Gamma_{1} \Delta \mathrm{X}_{\mathrm{t}-1}+\ldots+\Gamma_{\mathrm{k}-1} \Delta \mathrm{X}_{\mathrm{t}-\mathrm{k}+1}+\mu+\varphi \mathrm{D}_{\mathrm{t}}+\varepsilon_{\mathrm{t}}
$$

where a "star" after X on the right hand side of the equal sign indicates that the vector of the shares $(\mathrm{X})$ has been extended by the three price series.

\subsection{Analysis of the conditional system.}

When performing the residual analysis of the conditional system we find that both a VAR(1) and a VAR(2) are possible candidate models - and this time also the assumption of normality is fulfilled! Hence we choose the VAR(1) because the information criteria are smaller in this case ${ }^{9}$.

\footnotetext{
${ }^{9}$ As the misspecification tests are quite similar for a VAR(1) and a VAR(2) we base our choice of lag length on information criteria. By both the SC and HQ criteria the VAR(1) model is preferred with values being $\mathrm{SC}=-0.85$ and -0.37 and $\mathrm{HQ}=-1.43$ and -1.17 respectively for the $\operatorname{VAR}(1)$ and $\operatorname{VAR}(2)$. The misspecification test statistics and p-values are available from the authors upon request.
} 
We will not repeat the tests for the cointegration rank in the conditional system as the asymptotic distribution of the trace test will be affected by the presence of the conditioning variables. It is, however, not a problem as we can still rely on the conclusion we reached in the six-dimensional system with respect to the rank such that we have two cointegrating relations in the system. Identifying the two cointegrating relations as a relation for the share of beer and a relation for the share of wine, respectively leads to the following long-run relations:

The long-run relation for the share of beer:

$$
\text { Beer share }=-0.13456 \mathrm{~PB}+0.06455 \mathrm{PW}+0.02073 \mathrm{PS}-0.25400 \text { Trend }
$$

$$
\begin{array}{llll}
(0.03183) & (0.03215) \quad(0.00796) & (0.00681)
\end{array}
$$

The long-run relation for the share of wine:

$$
\begin{aligned}
\text { Wine share }= & 0.12189 \mathrm{~PB}-0.149920 \mathrm{PW}+0.05722 \mathrm{PS}+0.25016 \text { Trend } \\
& (0.02809) \quad(0.02837) \quad(0.00703)
\end{aligned}
$$

The values in parentheses below the estimates are the standard errors. It can be concluded that all parameters are significant at the $5 \%$ level. Furthermore, the sign of the coefficients are as expected from economic theory: when the own price increases the share of the corresponding category falls while the cross price effects are positive (which is expected for goods that are to some extent substitutes). The trend parameters indicate that the market share of beer declines by 0.25 percentage points every quarter even if the price relations are kept constant. The market share of wine correspondingly increases by 
0.25 percentage points every quarter while the market share of spirits as the redundant series has no trend. These trends are interpreted as measuring changes in taste, habits etc. in the Danish alcohol consumption.

As the loadings of the wine share relation is insignificant in the beer equation and vice versa $^{10}$ each category only adjusts towards equilibrium in relation to its own demand equation.

Finally, a system of short-run relations is estimated for the change in the share of beer and the change in the share of wine. The reporting of the system will be equation by equation even though full maximum likelihood estimation has been performed. In table 6 the results for the beer share equation is given and in table 7 the results for the wine equation can be found. The system seems well-specified when judged by the results of the misspecification tests. Even after our transformation of the model into a parsimonious one (The $\chi 2$-test of the zero restrictions that makes the parsimonious models admissible is: $\mathrm{Q}=3.48$ with a p-value of 0.75 ) it seems well-specified as judged by the usual battery of misspecification tests ${ }^{11}$.

The economic interpretation of the parsimonious system seems convincing: If the beer share is too high compared to the long-run relation (a positive Cil term) the beer share will adjust downwards (a negative coefficient in front of Ci1). Qualitatively the same mechanism works for the wine share.

\footnotetext{
${ }^{10}$ The speed-of-adjustment coefficient of wine in the beer equation is 0.081 with a standard error of 0.187 while the speed-of-adjustment coefficient of beer in the wine equation is 0.053 with a standard error of 0.181 .

${ }^{11}$ The results of the misspecification tests are available from the authors upon request.
} 
Table 6: Estimation of the short run equation for the change in the share of beer.

\begin{tabular}{|l|r|r|r|r|r|r|}
\hline & \multicolumn{2}{|l|}{ Full model } & \multicolumn{2}{l|}{ Parsimoneous model } \\
\hline Variable & \multicolumn{1}{|l|}{ Estimat } & \multicolumn{1}{l|}{ Std.err. } & p-value & \multicolumn{1}{l|}{ Estimat } & \multicolumn{1}{l|}{ Std.err. } & p-value \\
\hline Intercept & $59.508^{*}$ & 17.920 & 0.002 & $63.063^{*}$ & 6.655 & 0.000 \\
\hline $\begin{array}{l}\text { Change in } \\
\text { price of beer }\end{array}$ & -0.050 & 0.055 & 0.364 & - & - & - \\
\hline $\begin{array}{l}\text { Change in } \\
\text { price of wine }\end{array}$ & 0.027 & 0.063 & 0.670 & - & - & \\
\hline $\begin{array}{l}\text { Change in } \\
\text { price of spirits }\end{array}$ & 0.012 & 0.015 & 0.410 & - & - & \\
\hline Ci1-term & & & & & & \\
\hline Ci2-term & $-0.933^{*}$ & 0.211 & 0.000 & $-0.958^{*}$ & 0.101 & 0.000 \\
\hline
\end{tabular}

Technical comments to the tables: Ci1 is the deviation from the long-run beer share relation $\left(1^{\text {st }}\right.$ cointegration relation) while $\mathrm{Ci} 2$ is the deviation from the long-run wine relation $\left(2^{\text {nd }}\right.$ cointegration relation). A star indicates that the parameter is significant at the $5 \%$ level. (We are not removing any seasonal dummies they are just not shown in the tables).

Table 7: Estimation of the short run equation for the change in the share of wine.

\begin{tabular}{|l|r|r|r|r|r|r|}
\hline & \multicolumn{3}{|l|}{ Full model } & \multicolumn{2}{l|}{ Parsimoneous model } \\
\hline Variable & Estimat & Std.err. & p-value & Estimat & Std.err. & p-value \\
\hline Intercept & 20.449 & 16.740 & 0.228 & $23.777^{*}$ & 2.149 & 0.000 \\
\hline $\begin{array}{l}\text { Change in } \\
\text { price of beer }\end{array}$ & 0.024 & 0.051 & 0.635 & - & - & - \\
\hline $\begin{array}{l}\text { Change in } \\
\text { price of wine }\end{array}$ & -0.068 & 0.059 & 0.255 & $-0.061^{*}$ & 0.019 & 0.003 \\
\hline $\begin{array}{l}\text { Change in } \\
\text { price of spirits }\end{array}$ & $0.107^{*}$ & 0.014 & 0.000 & $0.116^{*}$ & 0.008 & 0.000 \\
\hline Ci1-term & 0.053 & 0.197 & 0.788 & & & - \\
\hline Ci2-term & $-0.999^{*}$ & 0.191 & 0.000 & $-0.992^{*}$ & 0.091 & 0.000 \\
\hline
\end{tabular}




\section{A forecasting exercise.}

With the short sample period of our study a formal recursive analysis of the stability of the model is impossible. Instead we consider a small forecasting exercise to serve that purpose. In addition the forecasting exercise may be viewed as an investigation into the ability of the model to be used for the policy analysis experiment of section 5.2. If able to come up with reliable predictions even during a period with a major change in a policy variable - the weakly exogenous price of spirits in the forecasting period - parameter invariance for this variable can be stated being one indicator that the Lucas critique ${ }^{12}$ will not apply to the model. This will allow the model to be used for policy analysis.

\subsection{One step ahead forecasts.}

In this section we will make a small forecasting exercise in order to assess how good the model is at predicting the effects of a major price change. From October $1^{\text {st }} 2003$ the price of spirits in Denmark experienced a large drop due to reductions of the taxes. Hence by re-estimating the model for a sample period that ends in $20032^{\text {nd }}$ quarter and afterwards predicting the development of the shares for the period $3^{\text {rd }}$ quarter 2003 and till $4^{\text {th }}$ quarter of 2004 conditional on the actual development in the three prices (based on one-step ahead predictions) we want to assess the forecasting ability of the twodimensional model. When doing one-step ahead forecasts we take as given the parameter estimates for the sample period $19903^{\text {rd }}$ quarter to $20032^{\text {nd }}$ quarter and in addition we assume that for each prediction we make that we know the immediate past. Also the prices of the prediction period are assumed known. Using one-step forecasts is a good way of investigating whether a model can capture the very short run effects of a change -

\footnotetext{
${ }^{12}$ For a text book discussion of super exogeneity and the Lucas critique, see e.g. Hendry (1995)
} 
here in one of the conditioning variables. The results of this forecasting exercise are shown in Figure 8 below. The top panel (DQBSHARE) shows the actual and predicted values for the change in the market share of beer while the bottom panel shows the actual and predicted values for the change in the market share for wine (DQWSHARE). The units on the y-axis are changes in percentage points.

$<$ Figure 8 about here $>$

The graph illustrates that the model is good at capturing the effects on the shares of the major change in the price of spirits in the autumn of 2003: for both the wine and the beer share the actual values are within the significance bounds of the forecasts. The only observation for which this is not the case is the one of the $4^{\text {th }}$ quarter of 2004 . A tentative explanation for this may be that this change in the shares was not primarily due to changes in the relative prices but rather to some other factor that apparently is not fully captured by the presence of the trend in the model. The actual observations are, however, not very far from the border of the bounds and we still believe that the present model simple as it is - is a good one!

\subsection{Market shares in scenarios with changes in the taxes on alcoholic beverages.}

In this section we try to predict the future market shares in a "no-change" scenario of the taxation compared to scenarios with what we believe are interesting possibilities for changes in the Danish taxation on alcoholic beverages.

In the first scenario we consider the situation where all taxes on alcoholic beverages are removed. This situation is of course a political impossibility in the Nordic countries, but it is the case in a large part of the world and in tax-free shops at e.g. airports. In the second scenario we consider the more realistic situation of the tax on spirits reduced to 
the level of that of beer and wine, as the European Commission (2004) argue that different taxations on alcohol is price discrimination and are introduced in order to protect a domestic market. Hence this scenario is a political possibility, as it is often argued that the Danish taxation on alcohol is in fact a restraint on trade. In the third scenario we assume that the Danish taxes on alcohol are reduced to exactly match the German ones, which is strongly advocated by the Danish retail sector in order to reduce the border trade.

The present econometric model gives us the possibility of deriving the consequences for the market shares for beer, wine and spirits but not for the actual sales figures. Of course reductions of the taxation on alcohol in Denmark would lead to increasing sales in Denmark, as it must be expected that Danes are less urged to travel to Germany and moreover Swedes and Norwegians will be even more willing to buy alcohol in Denmark. The model in this paper, however, gives no quantification of this increased sale. Yet the forecasts of the shifting market shares are also of interest to the Danish economy as the breweries play a fairly large role in the Danish labour market and more than half of the Danish sale of spirits is produced in Denmark while the Danish wine production is very small - almost non-existing.

We assume that the change in taxation took place in $1^{\text {st }}$ quarter of 2005 and that the price indices keep the new level after the tax change. For the "no change" scenario we let the price indices of $4^{\text {th }}$ quarter 2004 extend to the period of the forecasts (i.e. no price changes from $20044^{\text {th }}$ quarter and onwards). The calculations of hypothetical price indices after changes in taxation are of course only approximate, but still the results give an indication of the consequences for the market shares. Due to the fast error correction of our model we need only present the change in market shares for a few periods. 
Table 8 Results of simulation studies. Changes in market shares of beer, wine and spirits compared to a "no change" scenario.

\begin{tabular}{|l|r|r|r|r|r|r|r|r|r|}
\hline Quarter & \multicolumn{4}{|c|}{ Scenario (no taxes) } & \multicolumn{3}{|c|}{$\begin{array}{l}\text { Scenario2 (spirits down } \\
\text { to beer and wine) }\end{array}$} & \multicolumn{3}{c|}{$\begin{array}{c}\text { Scenario3 (German } \\
\text { taxes) }\end{array}$} \\
\hline Period & Beer & Wine & Spirits & Beer & Wine & Spirits & Beer & Wine & Spirits \\
\hline $1^{\text {st }} 2005$ & 0 & -6.78 & 6.79 & 0 & -5.61 & 5.61 & 0 & -0.80 & 0.80 \\
\hline $2^{\text {nd }} 2005$ & 0.71 & -2.86 & 2.15 & -1.16 & -2.53 & 3.69 & 0.94 & 0.61 & -1.55 \\
\hline $3^{\text {rd }} 2005$ & 0.74 & -2.82 & 2.08 & -1.21 & -2.50 & 3.71 & 0.98 & 0.62 & -1.60 \\
\hline $4^{\text {th }} 2005$ & 0.74 & -2.82 & 2.08 & -1.21 & -2.50 & 3.71 & 0.98 & 0.62 & -1.60 \\
\hline
\end{tabular}

The results of the first scenario reflect the price relations among the tax free beverages. In fact spirits has the lowest production costs while wine (as seen on the Danish market) is most expensive. The present taxation changes these price relations so that spirits is in fact far the most expensive type of alcohol in Denmark. A total relaxation of the taxes then makes spirits relatively much cheaper than today leading to an increasing market share. Moreover the taxations on beer and wine are almost equal today, but as the production cost of beer is the lowest a total removal of the taxes, changes the price relation between beer and wine in the direction of beer being cheaper.

$<$ Figure 9 about here $>$

In the second scenario where the level of taxation of spirits is reduced to match the level of taxation on beer and wine the market share of spirits increases by almost four percentage points. The negative effect on wine is about twice as big as the one for beer.

$<$ Figure 10 about here $>$ 
$<$ Figure 11 about here $>$

In the third scenario the results reflect the German taxation with mainly taxation on spirits, but at a lower level than in Denmark, while beer and wine are taxed much milder. A change of the Danish taxation to copy of the German taxation then increases the relative price of spirits and reduces the relative prices of beer and wine.

\section{Concluding remarks.}

In the present paper we have been analysing data for the Danish sale of alcohol. In the first part of the study we managed to demonstrate that the total sale measured in litres of $100 \%$ alcohol equivalents has been fairly stable since 1980 . Hence we do not find indications of a steady increase in spite of the increase in income and the tax reductions. In the second part of the study we focus on the distribution of the total sale into beer, wine and spirit. Using modern time series techniques we end up suggesting a parsimonious VECM model for the shares of beer and wine - a model in which the parameters have the expected signs in relation to economic theory both for the long- and the short run. In this model the income elasticity equals zero (i.e. income is not entering the model) and we conclude that changes in taste and habits are best approximated by inclusion of a trend. Furthermore, it is demonstrated that the model seems well suited to forecast the effects of even a major change in one of the category-prices. A model of the kind suggested in the present study also seems to be a valuable tool for predicting the effects on the market shares of changes in the relative prices of beer, wine and spirits for Denmark. 


\section{References.}

Andrikopoulos, A.A. \& Loizides, J. (2000) The demand for home-produced and imported alcoholic beverages in Cyprus: the AIDS approach, Applied Economics, 32, pp 1111-1119.

Bask, M. \& Melkersson, M. (2004) Rationally addicted to drinking and smoking?, Applied Economics, 36, 373-381.

Bentzen, J., Eriksson, T. \& Smith, V. (2001): Alcohol Consumption in European Countries. Time series based tests of convergence, Cahiers d'économie et sociologie rurales, no 60-61.

Bentzen, J. \& Smith, V. (2004): (Wine in) The Nordic countries. In Anderson, K ed.: The Worlds Wine Markets. Globalisation at work, Edward Elgar, London.

Bentzen, J \& Smith, V. (2005) Short-run and long-run relationships in the concumption of alcohol in the Scandinavian Countries, Nationaløkonomisk Tidsskrift (Danish Journal of Economics) Bd. 143, Nr 1, juni, pp. 65-80.

Blake, D. \& Nied, A. (1997), The demand for alcohol in the United Kingdom, Applied Economics, 29, pp 1655-1672

Bygvrå, Susanne (1998) The road to the Single European Market as seen through the Danish retail trade: Cross-border shopping between Denmark and Germany, The International review of Retail, Distribution and Consumer research 8:2

Eakins, J.M. \& Gallagher, L.A. (2003) Dynamic almost ideal demand systems: an empirical analysis of alcohol expenditure in Ireland, Applied Economics, 35, pp 10251036.

Edgerton, D.L., Assarsson, B., Hummelmose, A., Laurila, I.P., Rickertsen, K \& Vale, P.H. (1996) The Econometrics of Demand Systems. With applications to food demand in 
the Nordic countries. Advanced Studies in Theoretical and Applied Econometrics, vol 34, Kluwer Academic Publishers.

Commission of the European Communities (2004), Report from the Commission to the Council, the European Parliament and the European Economic and Social Committee on the Rates of Excise Duty Applied on Alcohol and Alcoholic Beverages, COM(2004) 223. Gallet, C.A. (1999) Gradual switching regression estimates of alcohol demand elasticities, Applied Economic Letters, 6, pp 377-379

Granger, C. \& Newbold, P (1974) Spurious Regressions in Econometrics, Journal of Econometrics 2, pp 111-120.

McGuinness(1980) An Econometric Analysis of Total demand for Alcoholic Beverages in the U.K., 1956-75, The Journal of Industrial Economics XXIX pp 85-109

Hendry, D. (1995): Dynamic Econometrics, Oxford: Oxford University Press.

Johansen, S. (1995) Likelihood-Based Inference in Cointegrated Vector Autoregressive Models, Oxford: Oxford University Press.

Johansen, S. (2000) A Bartlett Correction Factor for Tests on the Cointegrating Relations, Econometric Theory, 16, pp 740-778.

Johansen, S. (2002) A Small Sample Correction for the Test of Cointegration Rank in the Vector Autoregressive Model, Econometrica, vol 70, no 5, pp 1929-1961.

Kwiatkowsky, D. Phillips, P.C.B., Schmidt, P. \& Shin, Y. (1992) Testing the null hypothesis of stationarity against the alternative of a unit root. How sure are we that economic time series have a unit root?, Journal of Econometrics, 54, pp 159-17.

Lewbel (1996) Aggregation Without Separability: A Generalized Composite Commodity Theorem, The American economic review, 86, pp 524-543 
Lewbel (1997) Consumer Demand Systems and Household Equivalence Scales, Handbook of Applied Economtrics vol II 167-201 edited by Pesaran and Scmidt, Blackwell Publishers.

Milhøj, A. (1996) Structural changes in the Danish Alcohol Market, Nordic Alcohol Studies 13, pp 33-42.

Selvanathan, E.A. (1991) Cross-country alcohol consumption comparison: an application of the Rotterdam demand system, Applied Economics, 23, pp 1613-1622

Selvanathan, E.A. \& Selvanathan, S. (2004) Economic and demographic factors in Australian alcohol demand, Applied Economics, 36, pp 2405-2417

Thorsen, T. (1990) Hundrede års alkoholmisbrug: alkoholforbrug og alkoholproblemer i Danmark, Alkohol og narkotikarådet (in Danish). 
Figure 1A: The total sale of "pure" alcohol since 1980 ...

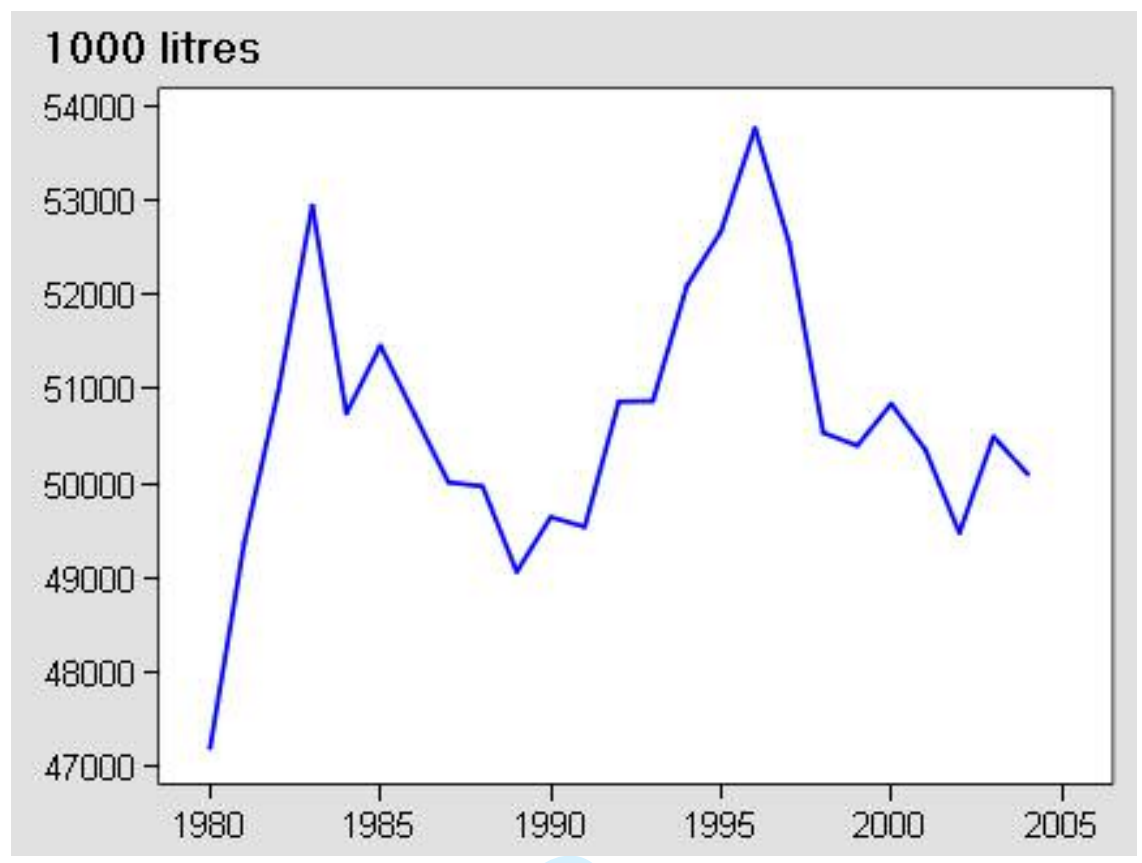

Figure 1B: And since 1903...

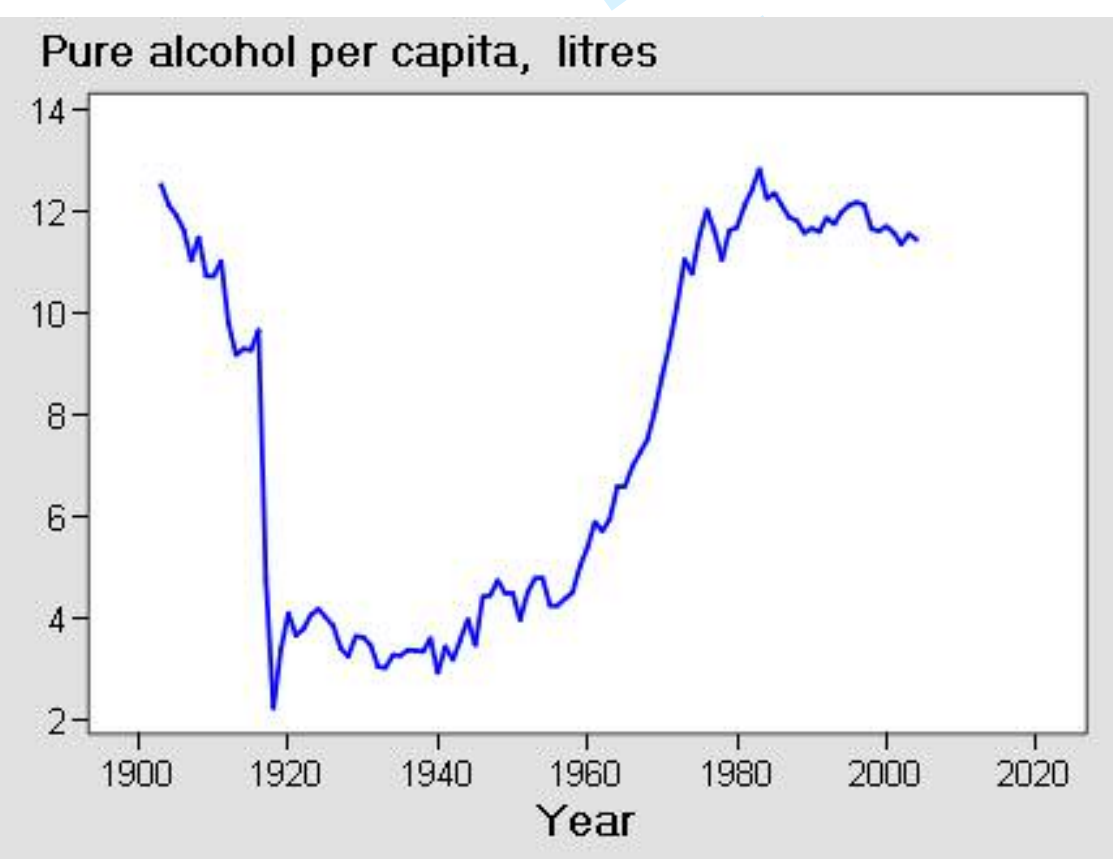


Figure 2: The development in the sale of alcohol and real income Index $=1981=100$

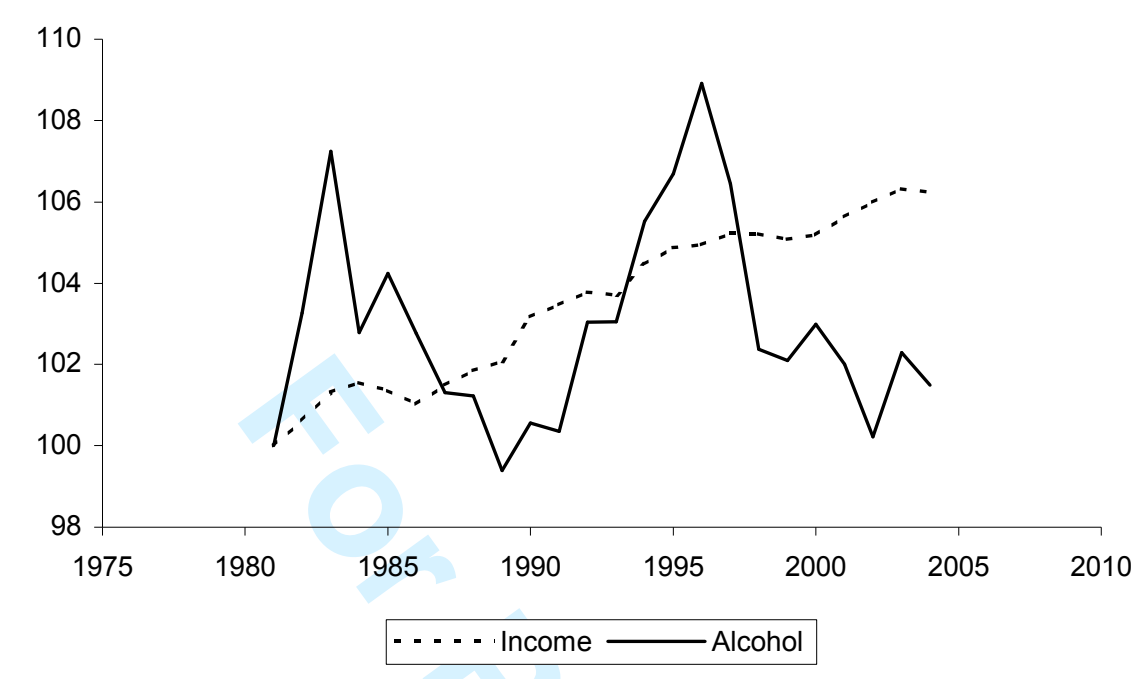


Figure 3: Yearly shares of beer, wine and spirits since 1980.

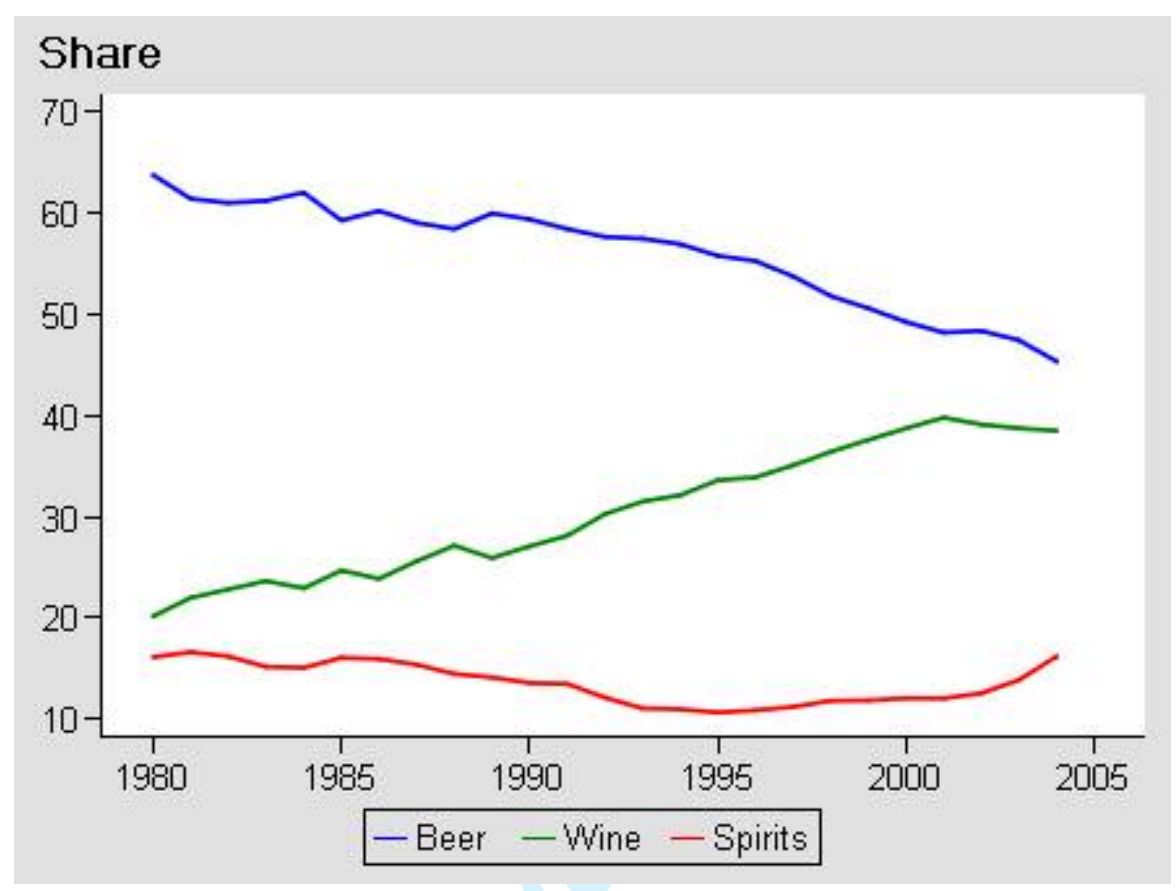


Figure 4: Quarterly shares 1990Q3-2004Q4

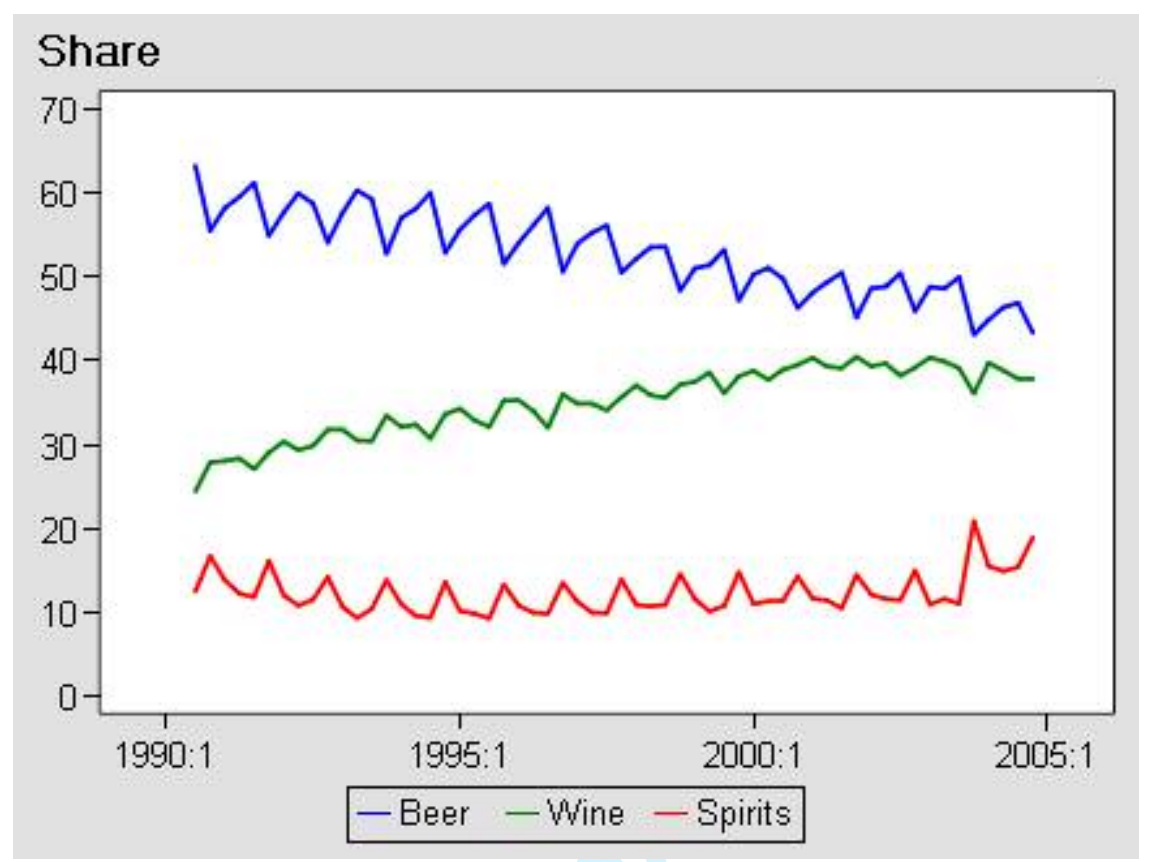


Figure 5A: Prices of alcohol.

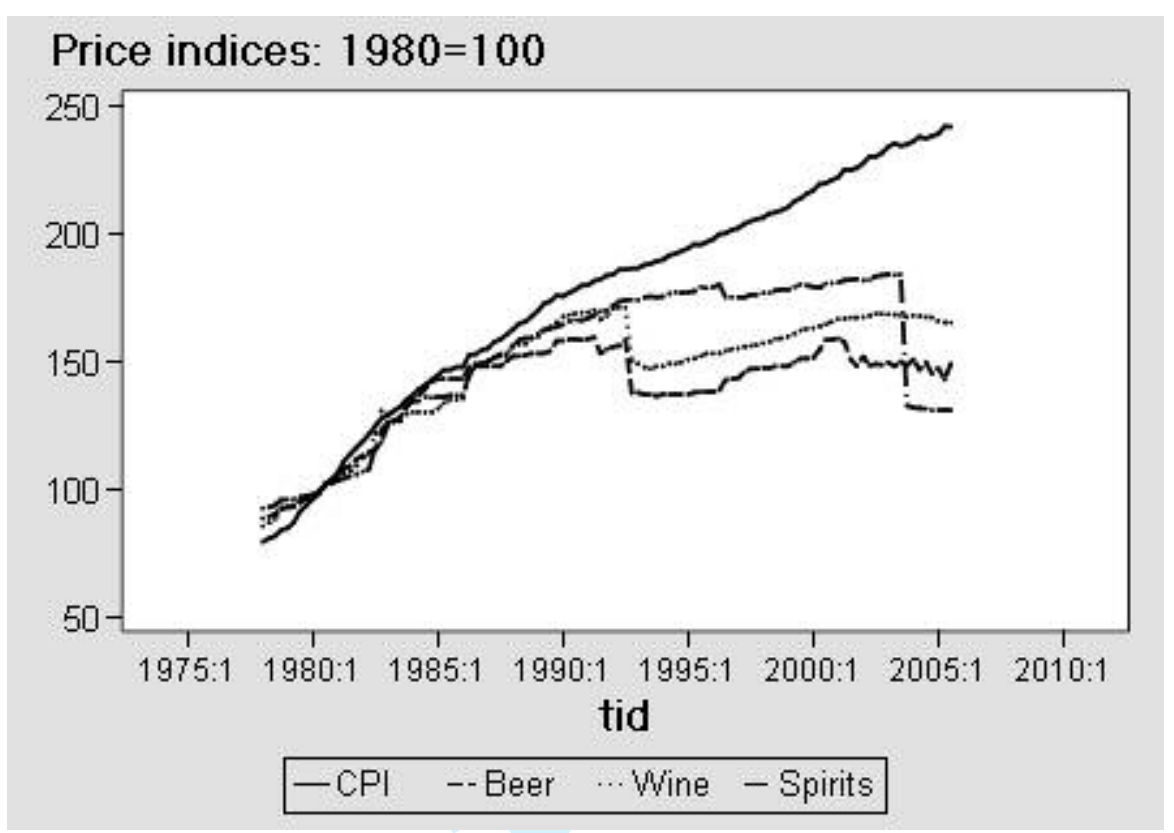

Figure 5B: Prices of alcohol in sample period.

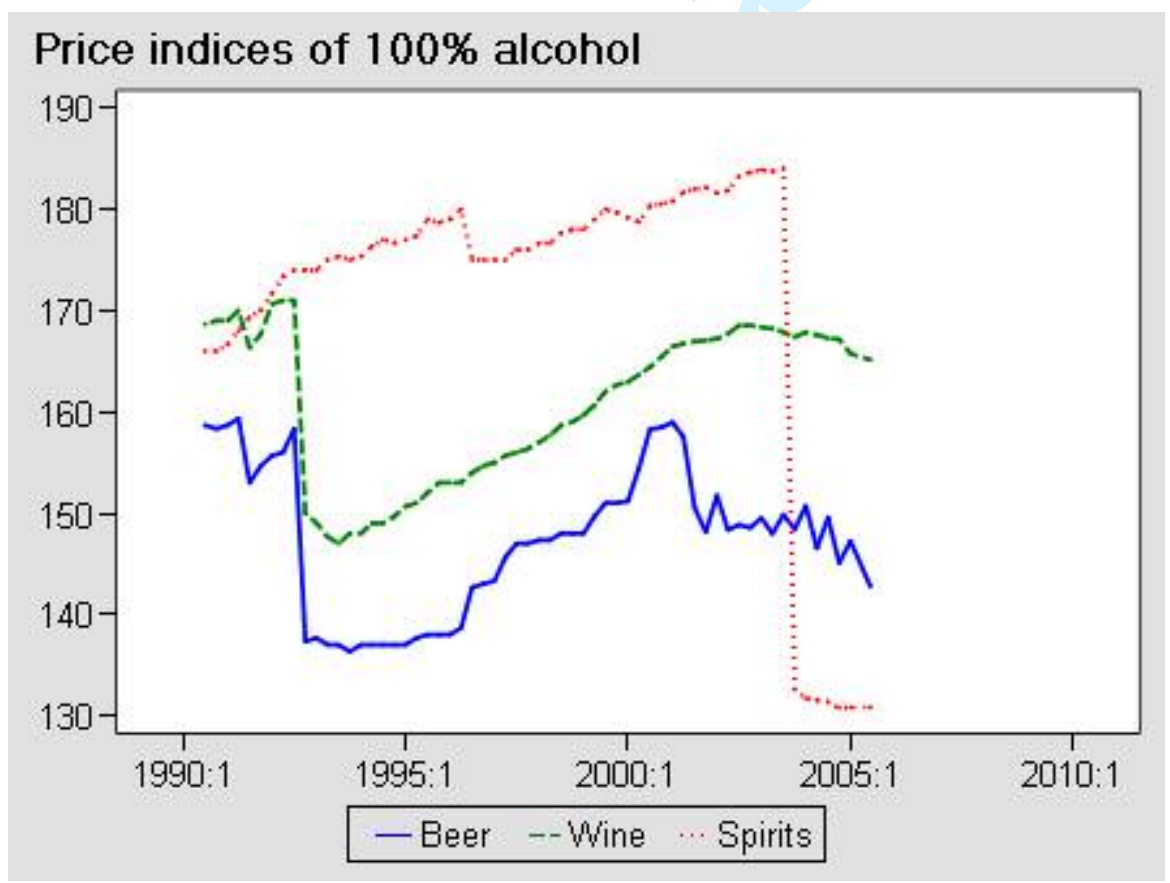


Figure 6: ACF of the total sale of alcohol.

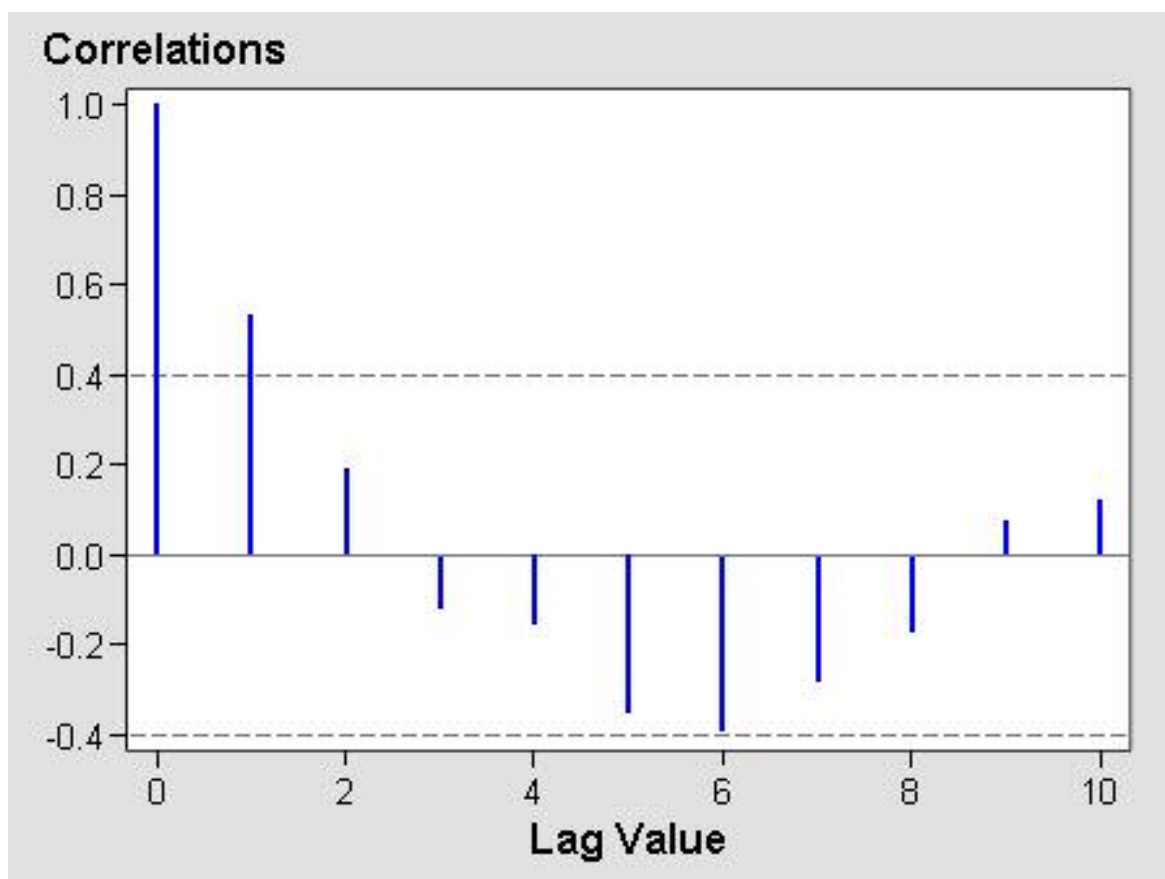


Figure 7A: The first cointegration relation. Upper panel shows the relation itself while the lower panel shows the relation after correction for short-run dynamics (incl. seasonal effects).

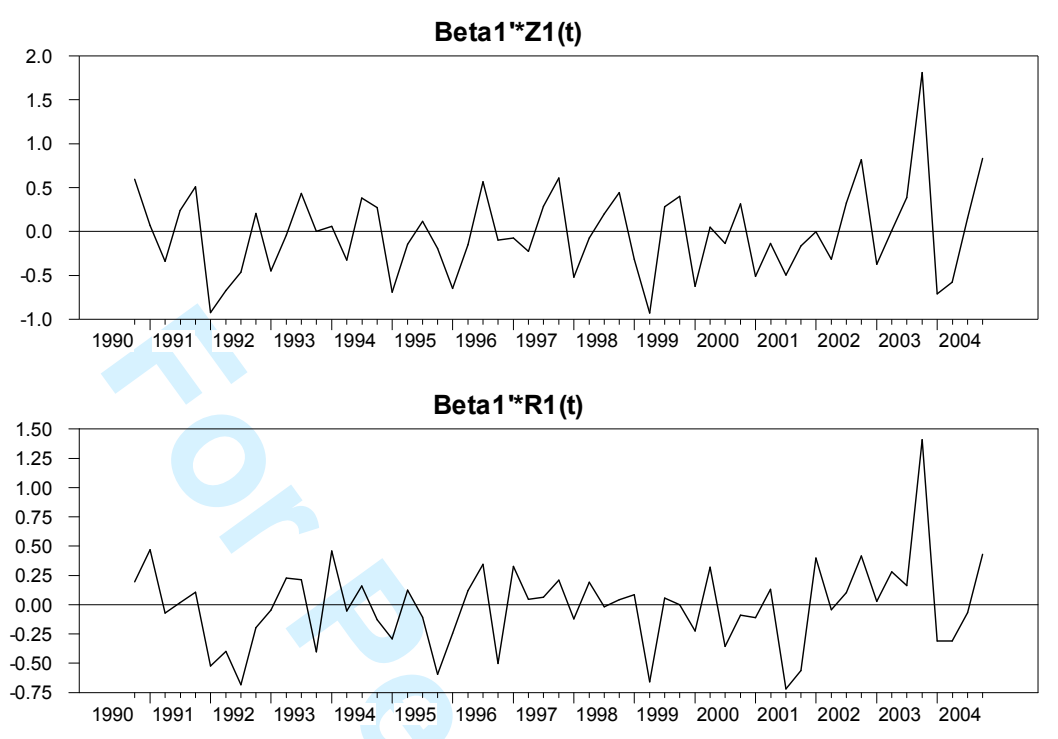

Figure 7B: The second relation. Interpretation of the panels as above.
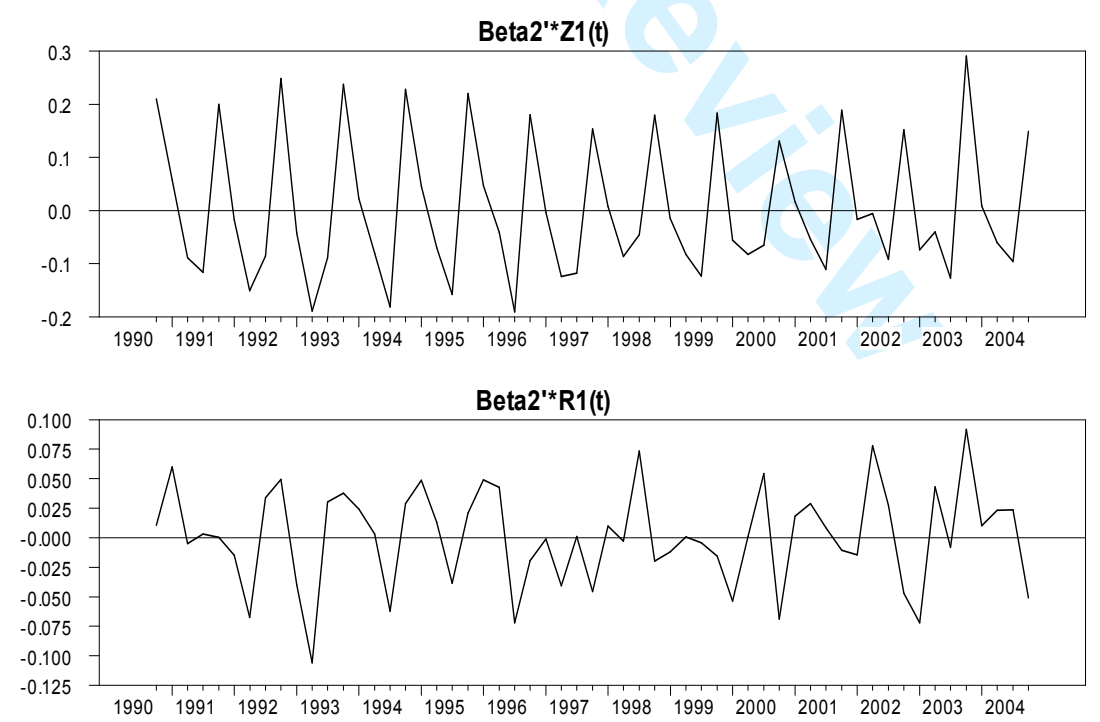
Figure 8: Results of the 1-step forecasts for the period $3^{\text {rd }}$ quarter 2003 till $2^{\text {nd }}$ quarter 2005.
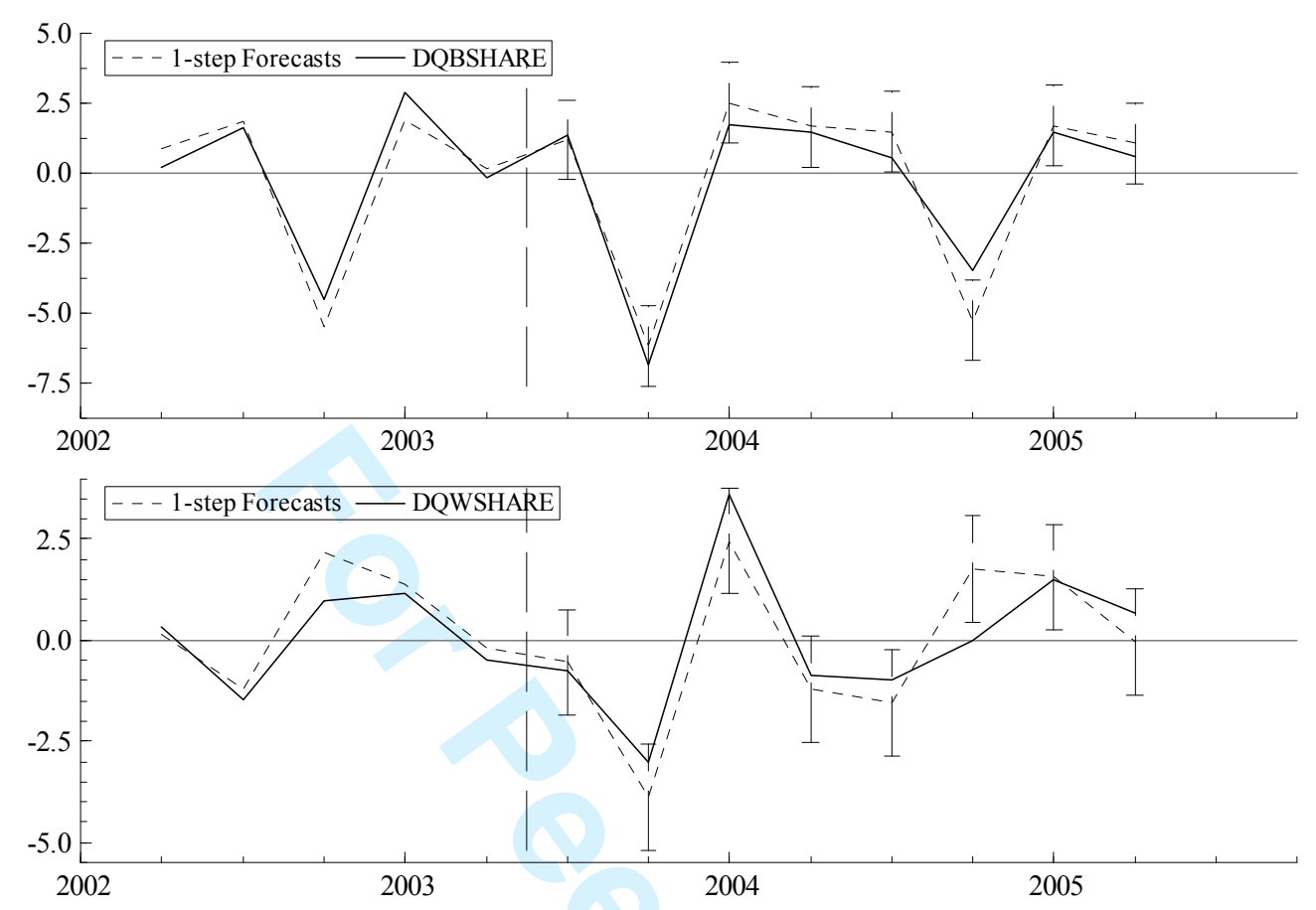
Figure 9: Comparisons of market share changes for scenario 1 - no taxes.

(B- refers to base scenario and F- refers to scenario with changed tax)

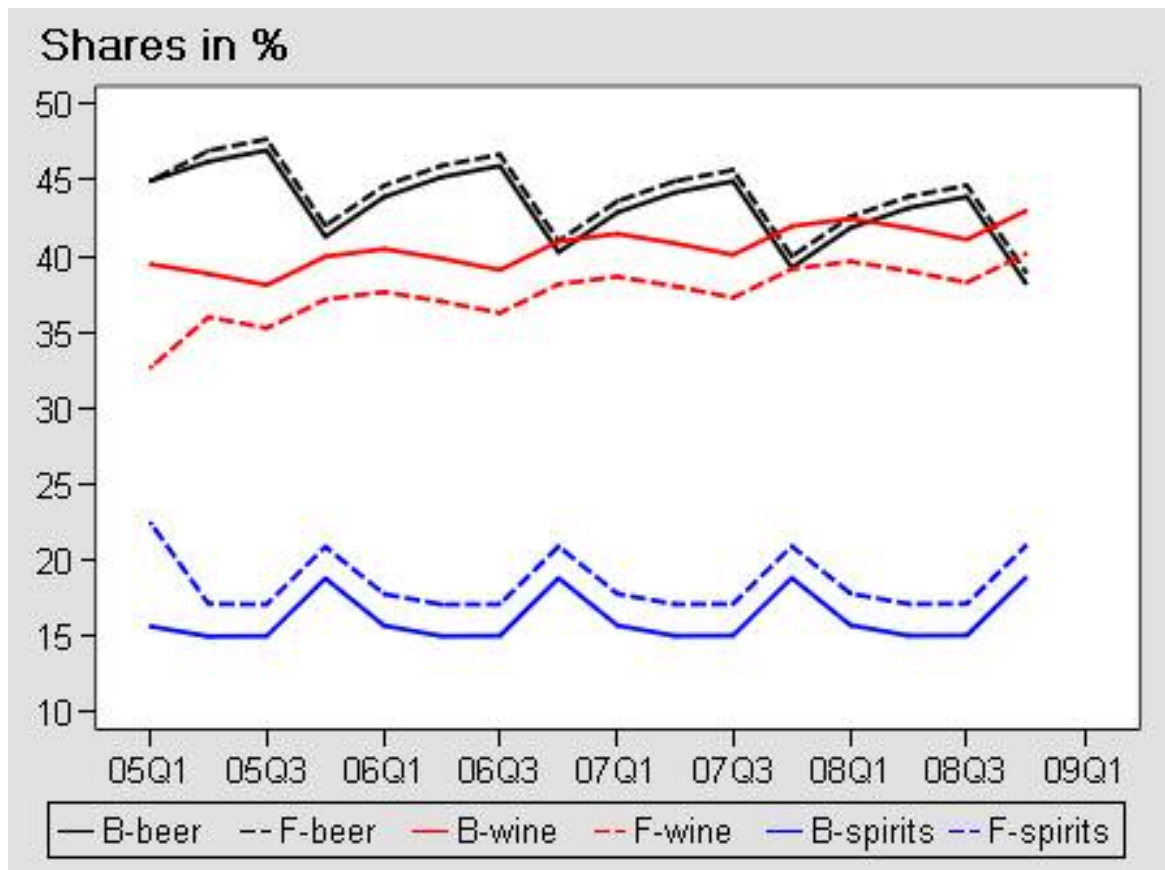

Figure 10: Comparisons of market shares changes for scenario 2 - spirits tax down. (B- refers to base scenario and F- refers to scenario with changed tax).

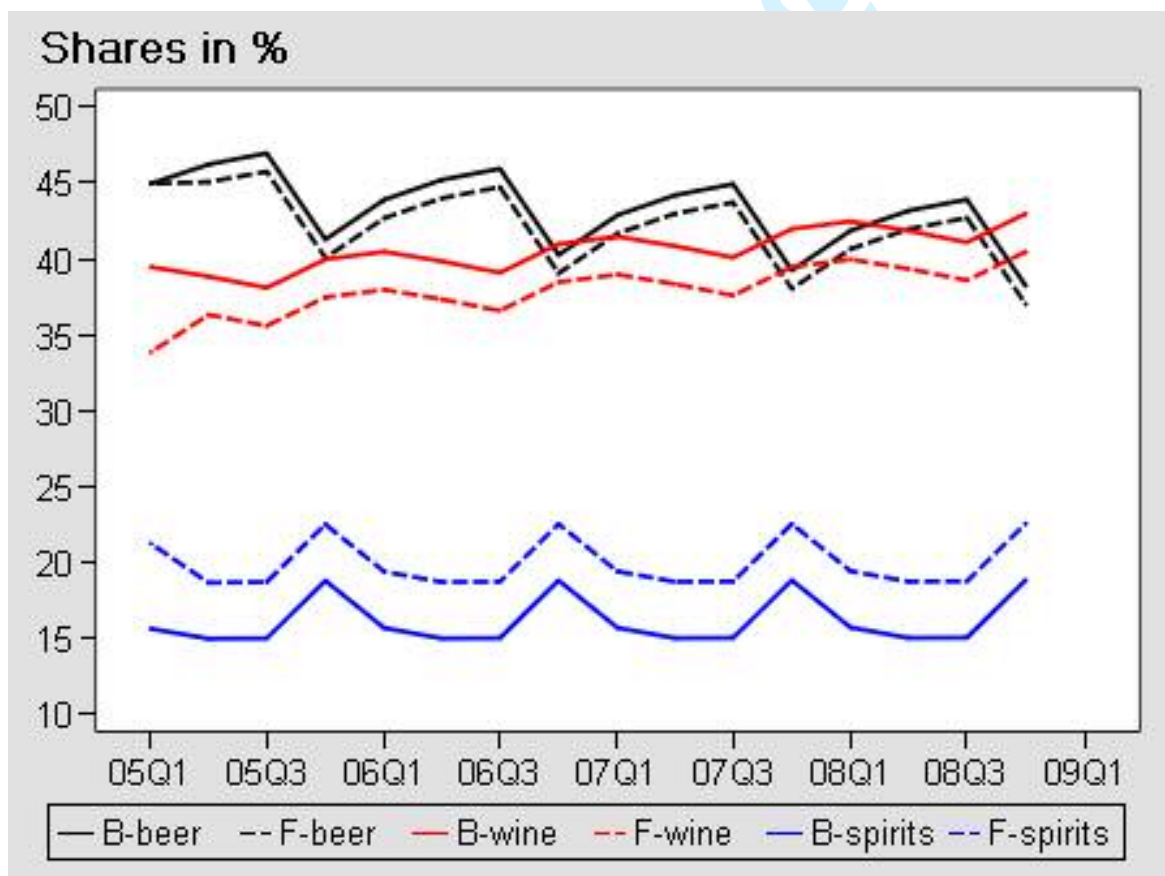


Figure 11: Comparisons of market shares changes for scenario 3 - German taxes. (B- refers to base scenario and F- refers to scenario with changed tax).

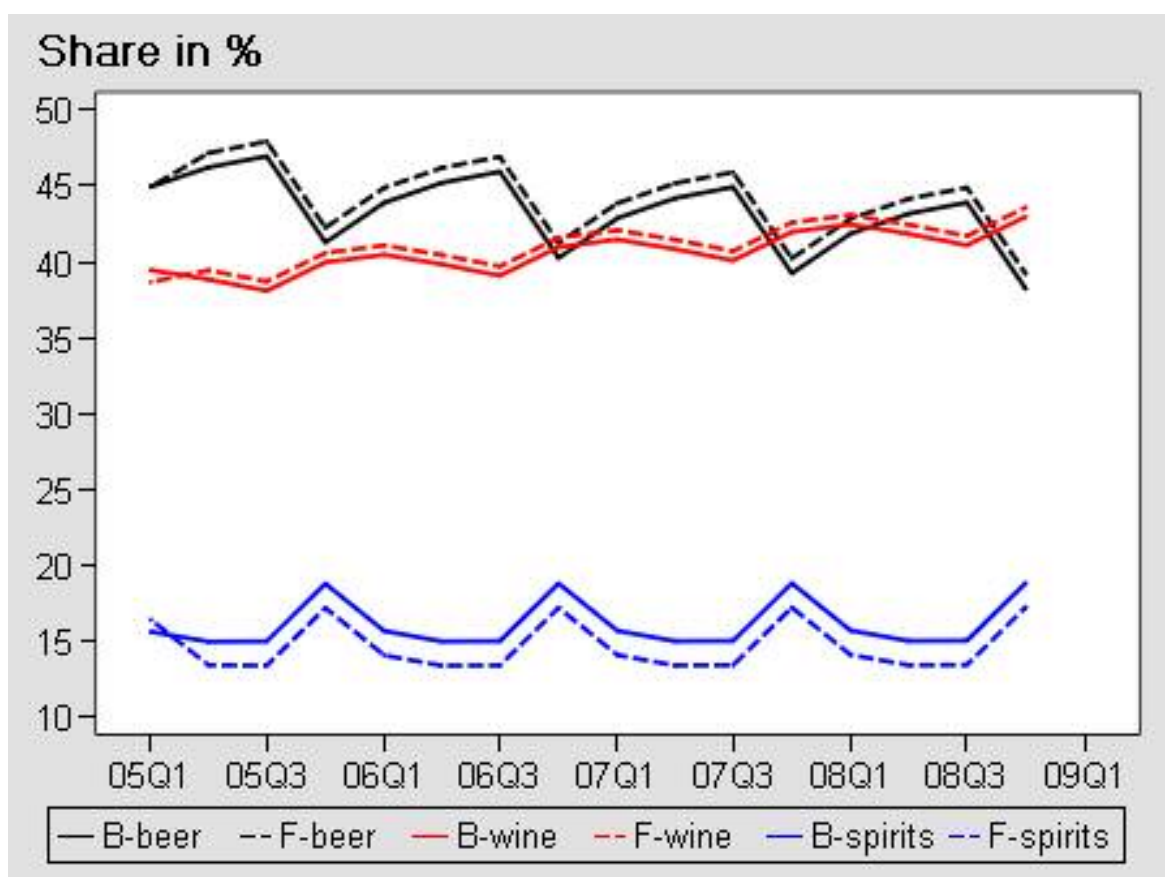

